\title{
Synthesis of Cadmium Oxide Nanoparticles by Electrochemical Method: Its Photodegradative Effects on Carboxylic Acids and Antibacterial Behaviours
}

\author{
H.C. Charan Kumar1, Rajegowda Shilpa ${ }^{1}$, Sanniaha Ananda ${ }^{2, *}$ \\ ${ }^{1}$ Departrment of Chemistry Manasagangotri, UOM, Mysuru - 570 006, Karanataka, India \\ ${ }^{2}$ Department of Chemistry, UGC-BSR Faculty, Manasagangotri, UOM, Mysuru - 570 006, Karanataka, India.
}

\section{ARTICLEDETAILS}

\section{Article history:}

Received 12 July 2019

Accepted 21 August 2019

Available online 19 September 2019

\section{Keywords:}

Electrochemical Method

CdO Nanoparticles

Carboxylic Acids

Volumetric Method

Antibacterial Activity

\begin{abstract}
A B S T R A C T
Cadmium oxide (CdO) nanomaterial has been synthesized by electrochemical method which is simple and inexpensive method. The synthesized cadmium oxide nanomaterial was used as a catalyst for the photocatalytic degradation of acetic acid, formic acid and oxalic acids under varies experimental conditions by volumetric method. The synthesized nanomaterials were characterized by various techniques such as UV-Visible spectroscopy, SEM-EDAX, FT-IR spectrum and X-ray diffraction studies. The UV-VIS spectroscopy study revealed that the band gap energy of cadmium oxide nanomaterials to be $2.85 \mathrm{eV}$ Tauc plot. The structure of cadmium oxide was found to be cubic structure and crystal size was found to be $32 \mathrm{~nm}$ which was confirmed from XRD data. SEM reports showed that the cadmium oxide nanomaterials have regular spherical shape and uniform size. The presence of cadmium and oxygen in the nanomaterial is confirmed from the EDAX spectrum. FT-IR spectra reveal the presence of characteristic band corresponds to $\mathrm{Cd}-\mathrm{O}$ mode. The photocatalytic activity of the synthesized cadmium oxide nanomaterial was examined by the kinetics of photodegradation of carboxylic acids by volumetric method by using $\mathrm{NaOH}$ solution. Taft LFER was tested the isokinetic temperature $\beta$ was calculated for oxidation of carboxylic acids. The antibacterial activity of cadmium oxide nanomaterial was investigated.
\end{abstract}

\section{Introduction}

Nanoparticles have enchanted prestigious awareness due to their individual chemical and physical properties, which are dissimilar from those of either the bulk materials or single atoms. Nanoparticles are of great awareness for many technical applications in dependent physical properties like fundamental research [1-4]. In recent days, many scholars have focused on metal oxide due to their applications in several areas of research, peculiarly in optoelectronic and other applications, including phototransistors, solar cells, transparent electrodes, photodiodes and gas sensors [5-6]. The nano sized metal powders have attained much influential in recent days due to their wide range of implementation in many fields. [7]. The oxides are stunning not only for scientific attentiveness but also for potential application in electronic, gas sensing and photonic devices [8-10]. Metal oxide nanomaterials are variety of size and shapes in nano regions. Now a days the transition metal oxide nanomaterials is leading a good roll in nano catalyst or degradation of dyes, organic compounds and also industrial effluents [10]. Cadmium oxide $(\mathrm{CdO})$ is one of the binary oxides having important electronic, structural, and optical properties. Recently, CdO-based TCOs have been of interest due to their relatively high carrier mobilities, simple crystal structures, and the possibility of being of nearly metallic conductivity [1114]. Cadmium oxide has a wide range of applications like the manufacture of paint pigments and cadmium-coated baths. Cadmium oxide has many applications due to its high optical transparency and low ohmic resistivity [15-17]. In recent years we observed that the metal oxide nanomaterials play a significant role in several areas of chemistry, materials science and physics. Cadmium oxide is one such material which takes over excellent optoelectronic and structural properties. Among the different metal oxide nanoparticles, cadmium oxide is an important $\mathrm{n}$-type semiconductor with a cubic structure, which belongs to the group of II-VI, with a direct band gap of 2.2 to $2.8 \mathrm{eV}$ and an indirect band gap of 1.36 to $1.98 \mathrm{eV} \mathrm{[18,19].} \mathrm{In}$ the present paper we synthesized cadmium oxide nanomaterials by electrochemical method which is an environmentally friendly method. The synthesized cadmium oxide nanomaterials on photodegradation of carboxylic acids by volumetric method by using $\mathrm{NaOH}$ solution and the kinetics of degradation of carboxylic acids were studied.

\section{Experimental Methods}

All chemicals were used to prepare cadmium oxide nanomaterials were the analytical grades of purity. Cadmium electrode was purchased from Alfa Aesar. Acetic acid, formic acid and oxalic acid from lobachemie, Platinum electrode from Elico Pvt. Ltd. All solutions were prepared in double distilled water. The optical properties for prepared cadmium oxide nanomaterials were studied by UV-visible spectrophotometer (shimadzu1700 series). The X-ray crystallographic interpretations were performed by X-ray diffractometer (Panalytical X-pert) using CuKa wavelength $(\lambda=1.54)$ scanning range from 0 to $70^{\circ}$. The morphological feature for the prepared cadmium oxide study was determined by scanning electron microscopy (SEM-EDEX) from quanta-200 FEI, Netherlands. The elemental analysis for the conformation of prepared $\mathrm{Cd}$ and $\mathrm{O}$ is confirmed from energy dispersive X-ray analysis (EDAX). The functional group present in the molecular structure was performed by FT-IR instrument by PerkinElmer Spectrum Version 10.03.09.

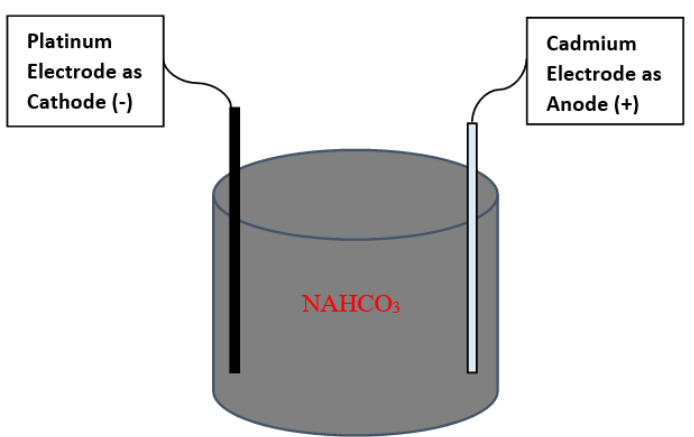

Fig. 1 Experimental set up for the electrochemical synthesis of cadmium oxide nanomaterial 


\subsection{Synthesis of Cadmium Oxide Nanomaterials by Electrochemical Method}

The cadmium oxide nanomaterial is synthesized by electrochemical method. The experimental process is as shown in Fig. 1. The Cadmium metal electrode is used as anode and platinum electrode is used as cathode. Using $20 \mathrm{~mA}$ current and potential of $10 \mathrm{~V}$ the experiment was run for $2 \mathrm{hr}$ with continues stirring. The electrolytic cell is consisting of 5 $\%$ of aqueous $\mathrm{NaHCO}_{3}$ solution. The distance of the anode and cathode during electrolysis was $2 \mathrm{~cm}$. During the electrolysis the cadmium electrode starts to dissolve and give cadmium ions, which are electrochemically reacted with $\mathrm{NaHCO}_{3}$ to give solid cadmium oxide. The obtained solid cadmium oxide is washed with double distilled water till complete removal of unreacted $\mathrm{NaHCO}_{3}$. The solid cadmium oxide is centrifuged and calcined for $2 \mathrm{~h}$ at $800{ }^{\circ} \mathrm{C}$ for dehydration and for the removal of hydroxides to get cadmium oxide nanomaterial. The redox potential of $\mathrm{Cd}(-0.40)$. The ionic radius of $\mathrm{Cd}^{2+}$ is $0.95 \AA$ A respectively. Since the mechanism for the synthesized cadmium oxide nanomaterial is given in Scheme 1.

\begin{tabular}{|c|c|c|}
\hline $\begin{array}{l}\mathrm{Cd} \\
2 \mathrm{NaHCO}_{3}+2 \mathrm{e}^{-} \\
\mathrm{Cd}^{2+}+2 \mathrm{OH}^{-} \\
\mathrm{Cd}(\mathrm{OH})_{2}\end{array}$ & $\stackrel{\longrightarrow \longmapsto}{\longrightarrow}$ & $\begin{array}{l}\mathrm{Cd}^{2+}+2 \mathrm{e}^{-} \\
2 \mathrm{CO}_{2}+2 \mathrm{Na}+2 \mathrm{OH}^{-} \\
\mathrm{Cd}\left(\mathrm{OH}^{-}\right)_{2} \\
\mathrm{CdO}+\mathrm{H}_{2} \mathrm{O}\end{array}$ \\
\hline $\mathrm{Cd}+2 \mathrm{NaHCO}_{3}$ & 4 & $\mathrm{CdO}+\mathrm{CO}_{2}+2 \mathrm{Na}+\mathrm{H}_{2} \mathrm{O}$ \\
\hline
\end{tabular}

In general,

Metal $+\mathrm{NaHCO}_{3} \longrightarrow \longrightarrow \mathrm{CdO}+\mathrm{CO}_{2}+\mathrm{Na}+\mathrm{H}_{2} \mathrm{O}$

The overall retroaction $\mathrm{Cd}+\mathrm{NaHCO}_{3} \longrightarrow \mathrm{CdO}$ Nanomaterial

Scheme 1 Mechanism for the synthesized cadmium oxide nanomaterial

\subsection{Determination of Photocatalytic Activities}

Oxalic acid properties: molecular formula - $\mathrm{C}_{2} \mathrm{H}_{2} \mathrm{O}_{4}$, Molar mass - 90.034 gmol-1 ${ }^{1}$, formic acid properties: molecular formula - $\mathrm{CH}_{2} \mathrm{O}_{2}$, molar mass 46.025 gmol-1 $^{-1}$, acetic acid properties: molecular formula: $\mathrm{C}_{2} \mathrm{H}_{4} \mathrm{O}_{2}$, molar mass - $60.052 \mathrm{gmol}^{-1}$. The different concentration of acid solutions $\left(0.5 \times 10^{\text {- }}\right.$ ${ }^{3}$ to $3 \times 10^{-3} \mathrm{M}$ ) were prepared by dissolving in distilled water. This solution was used as a test contaminant for evaluating photocatalytic activities of the prepared cadmium oxide nanomaterial. The exploration was carried out under tungsten-halogen UV-light in order to check the effectiveness of cadmium oxide nanomaterial. The COD has been reported both before degradation and after degradation of all the carboxylic acids solution using dichromate oxidation method $[20,21]$. COD effect was calculated by the following equations.

$$
\text { COD }=(\text { Blank }- \text { Sample }) \times N_{\text {FAS }} \times 8000 / \text { V Sample }
$$

\subsection{Kinetics of Photodegradation by Volumetric Method}

Volumetric analysis is widely used quantitative analytical method. This method involves the measurement of volume of a solution of known concentration which is used to determine the concentration of the analyte. In the present manuscript the volumetric titration method was used to determine the degradation efficiency, by measuring the concentration of carboxylic acid by the titration against sodium hydroxide solution at different time intervals. After complete degradation of carboxylic acid, no colour formation takes place with phenolphthalein- $\mathrm{NaOH}$ solution. A plot of $\log \mathrm{V} / \mathrm{V}_{0}$ versus time was linear up to $60 \%$ of the reaction illustrate the appearance of carboxylic acid follows first order kinetics.

\section{Results and Discussion}

\subsection{UV-Visible Spectra}

The optical parameters like optical absorption and optical transmittance are the two important properties to be considered in the fabrication of optical devices. It is confirmed that from the optical absorption spectra, the absorption band of the cadmium oxide nanomaterial had been showing a blue shift which is due to particle size in nano region $[22,23]$. The synthesized cadmium oxide nanomaterial has showed that maximum intensity peak at $299.75 \mathrm{~nm}$ in the UV-region and there is no absorption peak in the visible region (Fig. 2), Further, the rate of degradation of carboxylic acids in presence of sunlight is very slow compare to UV light. The UV-Visible spectrum of cadmium oxide nanomaterial over the range $200-700 \mathrm{~nm}$ showed that the synthesized nanomaterial is photoactive under ultraviolet radiation. The band gap of synthesized cadmium oxide nanomaterial was calculated using Tauc plot https://doi.org/10.30799/jnst.278.19050505
[24] by plotting $(\alpha \mathrm{hm})^{1 / 2}$ verses h $\gamma$. The band gap energy could be thus estimated to be $2.85 \mathrm{eV}$ for cadmium oxide nanomaterial.
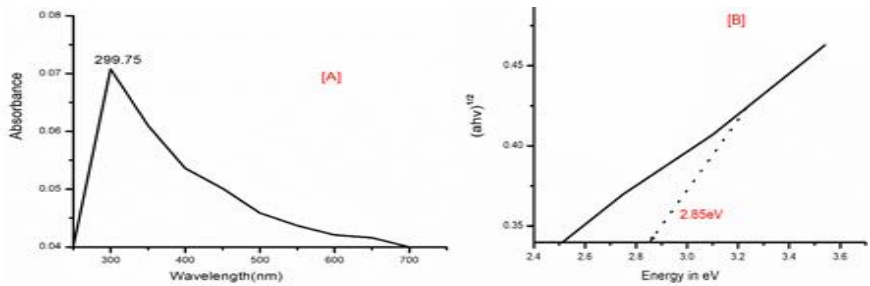

Fig. 2 UV-visible spectra (A) and Tauc plot (B) of cadmium oxide nanomaterial

\subsection{X-Ray Diffraction}

The XRD pattern from Fig. 3 indicates the crystallinity and purity of the synthesized cadmium oxide nanomaterial. The position of the peak appearing at 2 theta is $33.10,38.40,55.44,66.11,69.46$ can be readily indexed as (111), (200), (220), (311), (222) crystal plans of the cadmium oxide nanomaterial. All these diffraction peaks can be perfectly matched with respect to their position with cubic crystal structure and crystal size was found to be $32 \mathrm{~nm}$ from the XRD pattern using the Debye-scherrers formula $[25,26], \mathrm{D}=\mathrm{k} \lambda / \beta \cos \theta$, where $\mathrm{k}$ is an empirical constant equal to $0.9, \lambda$ is the wavelength of the $X$-ray source, $\beta$ is the full width at half maximum of the diffraction peak and $\theta$ is the angular position of the peak. With reference to the JCPDS \# 65-2908 standards. The peak at $33.10^{\circ}$ reflects (111) planes, $38.40^{\circ}$ reflects $(200)$ planes, $55.44^{\circ}$ reflects $(220)$ planes, $66.11^{\circ}$ reflects (311) planes and $69.46^{\circ}$ reflects (222) planes. Hence XRD analysis clearly indicates the presence of cadmium oxide nano composition.

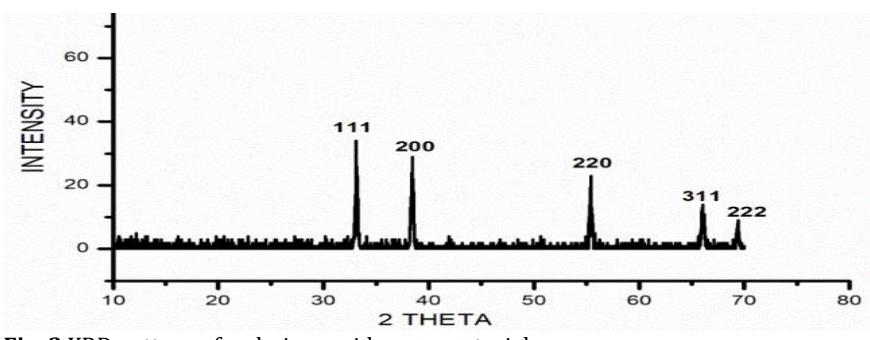

Fig. 3 XRD pattern of cadmium oxide nanomaterial

\subsection{Scanning Electron Microscopy (SEM)}

The SEM morphology of the cadmium oxide nanomaterial is shown in Fig. 4. From the figure it is clear that the particles were agglomerated in nature. The SEM image shows randomly distrubuted cadmium oxide grains with smaller size. Hence it is concluded that the formation of nanomaterial have regular spherical shape and uniform size. The EDAX spectrum conformed the presence of cadmium and oxygen in the nanomaterial. The atomic percentage composition of the elements cadmium and oxygen were observed to be equal to $44.15 \%$ and $55.85 \%$ (Fig. 5 and Table 1)

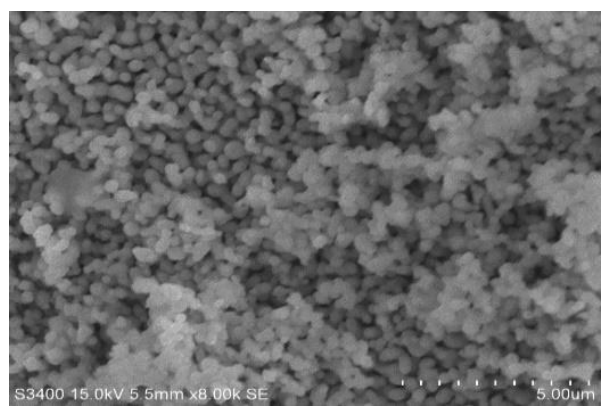

Fig. 4 SEM images of electrochemically synthesized Cadmium oxide nanomaterial

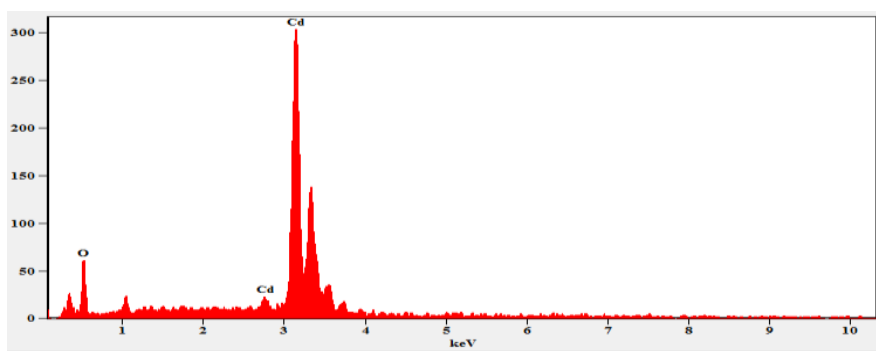

Fig. 5 Energy dispersive X-ray analysis spectrum of cadmium oxide nanomaterial 
Table 1 Quantitative results for cadmium oxide nanomaterial

\begin{tabular}{llll}
\hline Element Line & Weight\% & Weight\% Error & Atom\% \\
\hline O K & 15.26 & \pm 2.90 & 55.85 \\
Cd L & 84.74 & \pm 3.01 & 44.15 \\
Cd M & --- & & --- \\
Total & 100.00 & & 100.00 \\
\hline
\end{tabular}

\subsection{FTIR Analysis}

Fourier transform infrared spectroscopy (FT-IR) is an effective tool used to identify the functional groups present in the studied material. The modes of vibration of chemical bonds present in the cadmium oxide nanomaterial were analyzed from the FT-IR spectrum Fig. 6 and the functional groups were recorded in the range of $400-4000 \mathrm{~cm}^{-1}$. The peak corresponding to wagging vibration of pure $\mathrm{CdO}$ is observed at $1425 \mathrm{~cm}^{-1}$. The characteristic bands in the range of $400-700 \mathrm{~cm}^{-1}$ correspond to $\mathrm{Cd}-\mathrm{O}$ mode. The peaks observed at around $462.88 \mathrm{~cm}^{-1}$ and $850.12 \mathrm{~cm}^{-1}$ corresponds to the formation of symmetric and asymmetric vibration frequencies of $\mathrm{Cd}$ and $\mathrm{O}$ bond. The spectrum reveals absorption bands at around $545.6 \mathrm{~cm}^{-1}$ and $408.1 \mathrm{~cm}^{-1}$. These bands are due to $\mathrm{Cd}^{2+-} \mathrm{O}^{2-}$ stretching vibrations on tetrahedral and octahedral sites [27-29].

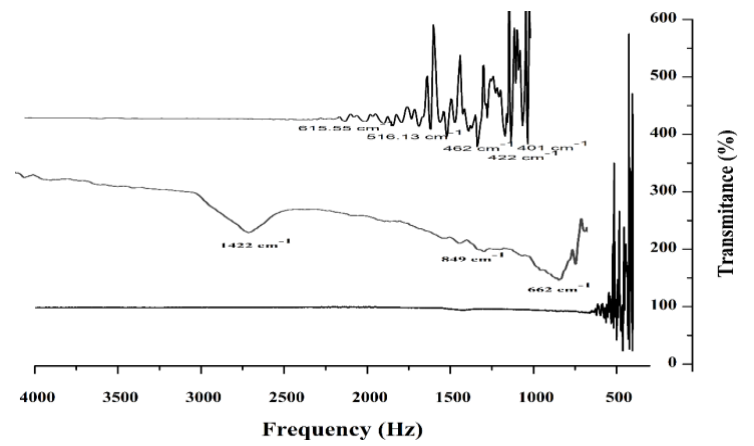

Fig. 6 FTIR spectrum of cadmium oxide nanomaterial

\subsection{Photodegradation Kinetics and COD Measurements}

\subsubsection{Effect of Concentration of Carboxylic Acids}

The photodegradation with different concentration of carboxylic acids solution $\left(0.5 \times 10^{-3}\right.$ to $\left.3 \times 10^{-3}\right)$ with constant weight of cadmium oxide nanomaterial as a photocatalyst was carried out. The change in concentration of the carboxylic acids was recorded by appearance of colour using sodium hydroxide solution by volumetric method. A plot of $\log \mathrm{V} / \mathrm{V}_{0}$ versus time was linear up to $60 \%$ of the reaction illustrate the disappearance of carboxylic acid follows first order kinetics (Figs. 7 and 8). The rate constant values are given in Table 2 and the reaction rate decreased with increase in acid solutions. The logic beyond that is with increase in the acid concentration, the solution becomes more intense and the path length of the photons entering the solution is decreased and the few photons reached the catalyst surface. Hence the production of hydroxyl radicals is reduced. Therefore, the Photodegradation efficiency is reduced. The COD for acid solutions before and after degradation were measured and are given in Table 2. To account for the mineralization of acids solution COD was examined at different stage. The formation of different radical species during photodegradation is given in Scheme 2. The carboxylic acid solution was found to have mineralized into $\mathrm{H}_{2} \mathrm{O}, \mathrm{CO}_{2}$ and simpler inorganic salts [30,31]. The photodegradation efficiency of the photo catalyst was calculated by the following formula,

Photodegradation efficiency $=$ Initial COD - Final COD x100/ Initial COD

$$
\begin{array}{ll}
\mathrm{e}_{\mathrm{cb}}^{-} \mathrm{O}_{2} & \longrightarrow \mathrm{O}_{2}^{-} \\
\mathrm{h}^{+}{ }_{\mathrm{vb}}+\mathrm{H}_{2} \mathrm{O} & \longrightarrow \mathrm{H}^{+}+\mathrm{OH} \\
\mathrm{O}_{2}^{-}+\mathrm{H}^{+} & \longrightarrow \mathrm{HO}_{2} \\
\mathrm{HO}_{2}+\mathrm{e}_{\mathrm{cb}}^{-}+\mathrm{H}^{+} & \longrightarrow \mathrm{H}_{2} \mathrm{O}_{2} \\
\mathrm{H}_{2} \mathrm{O}_{2}+\mathrm{O}_{2}^{-} & \longrightarrow \mathrm{OH}_{2}^{-} \mathrm{OH}+\mathrm{O} \\
\mathrm{OH}+\text { Carboxylic acid } & \longrightarrow \mathrm{CO}_{2}+\mathrm{H}_{2} \mathrm{O}+\text { Simple inorganic salts }
\end{array}
$$

Scheme 2 Mechanism for the photodegradation of carboxylic acids

\subsubsection{Effect of Catalyst Loading}

The experiments were carried out by taking different amount of catalyst varying from 0.002 to $0.02 \mathrm{~g}$ keeping acid concentration constant in order to study the effect of catalyst loading. The study showed that increase in catalyst loading from 0.002 to 0.02 g increased acid efficiency. Further increase in catalyst above $0.02 \mathrm{~g}$ decreased the photoactivity of the catalyst, due to aggregation of cadmium oxide nanomaterials at higher https://doi.org/10.30799/jnst.278.19050505 concentration causing a decrease in the number of active sites on catalyst

\begin{tabular}{|c|c|c|c|c|c|c|c|}
\hline \multirow[t]{2}{*}{$\begin{array}{l}\text { Catalyst } \\
0.01 \mathrm{~g}\end{array}$} & \multirow[t]{2}{*}{$\begin{array}{l}\text { Carboxylic } \\
\text { acids }\end{array}$} & \multirow{2}{*}{$\begin{array}{l}\text { Conc. of } \\
\text { acids in } \\
10^{3}(\mathrm{M})\end{array}$} & \multirow[t]{2}{*}{$10^{3} \mathrm{k} \mathrm{sec}^{-1}$} & \multirow[t]{2}{*}{$\begin{array}{l}\text { Time*, } \\
\text { min }\end{array}$} & \multicolumn{2}{|c|}{$\begin{array}{l}\text { COD Values } \\
\text { in } \mathrm{mg} / \mathrm{L}\end{array}$} & \multirow[t]{2}{*}{$\begin{array}{l}\text { Efficiency } \\
\%\end{array}$} \\
\hline & & & & & Before & After & \\
\hline & Oxalic acid & 0.5 & 9.82 & 5 & 512 & 16 & 96.87 \\
\hline & & 1.0 & 3.54 & 20 & 816 & 48 & 94.11 \\
\hline & & 2.0 & 0.77 & 160 & 992 & 32 & 96.77 \\
\hline $\mathrm{CdO}$ & & 3.0 & 0.31 & 220 & 1216 & 32 & 97.36 \\
\hline \multirow[t]{8}{*}{ NPs } & Formic & 0.5 & 8.36 & 8 & 464 & 16 & 96.55 \\
\hline & acid & 1.0 & 2.43 & 30 & 672 & 32 & 95.23 \\
\hline & & 2.0 & 0.52 & 190 & 816 & 48 & 94.11 \\
\hline & & 3.0 & 0.18 & 280 & 992 & 32 & 96.77 \\
\hline & Acetic acid & 0.5 & 6.52 & 10 & 368 & 32 & 91.30 \\
\hline & & 1.0 & 1.88 & 40 & 544 & 16 & 97.05 \\
\hline & & 2.0 & 0.43 & 155 & 624 & 32 & 94.87 \\
\hline & & 3.0 & 0.27 & 300 & 704 & 24 & 96.59 \\
\hline
\end{tabular}
surface \& increase in the light scattering of cadmium oxide nanomaterial at high concentration [32,33]. This tends to decrease the passage of light through the sample. Further, the present study indicated, from economic point of view, the optimized photocatalyst loading is $0.01 \mathrm{~g} / 20 \mathrm{~mL}$ (Figs. 9 and 10; and Table 3).

Table 2 Effect of photodegradation at different concentration of carboxylic acids under UV light

*for 95\% Degradation
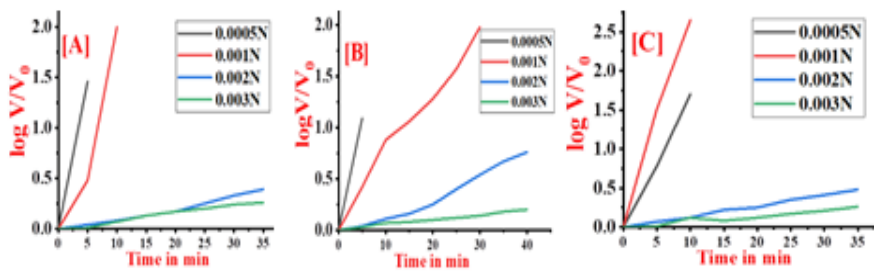

\begin{tabular}{|c|c|c|c|c|c|c|}
\hline \multirow{2}{*}{$\begin{array}{l}\text { Carboxylic } \\
\text { acids }\end{array}$} & \multirow{2}{*}{$\begin{array}{l}\text { CdO } \\
\text { NPs }\end{array}$} & \multirow[t]{2}{*}{$10^{3} \mathrm{k} \mathrm{sec}^{-1}$} & \multirow{2}{*}{$\begin{array}{l}\text { Time, } \\
\text { min }\end{array}$} & \multicolumn{2}{|c|}{ COD Values in $\mathrm{mg} / \mathrm{L}$} & \multirow[t]{2}{*}{ Efficiency \% } \\
\hline & & & & Before & After & \\
\hline Oxalic acid & $0.002 \mathrm{~g}$ & 0.71 & 180 & 816 & 16 & 98.03 \\
\hline \multirow[t]{3}{*}{$1.0 \times 10^{-3}$} & $0.005 \mathrm{~g}$ & 0.98 & 120 & 816 & 32 & 96.07 \\
\hline & $0.01 \mathrm{~g}$ & 3.54 & 20 & 816 & 48 & 94.11 \\
\hline & $0.02 \mathrm{~g}$ & 7.67 & 10 & 816 & 32 & 96.07 \\
\hline Formic acid & $0.002 \mathrm{~g}$ & 0.52 & 190 & 672 & 16 & 97.61 \\
\hline \multirow[t]{3}{*}{$1.0 \times 10^{-3}$} & $0.005 \mathrm{~g}$ & 0.72 & 140 & 672 & 48 & 92.85 \\
\hline & $0.01 \mathrm{~g}$ & 2.43 & 30 & 672 & 32 & 95.23 \\
\hline & $0.02 \mathrm{~g}$ & 6.44 & 18 & 672 & 16 & 97.61 \\
\hline Acetic acid & $0.002 \mathrm{~g}$ & 0.40 & 210 & 544 & 32 & 94.11 \\
\hline \multirow[t]{3}{*}{$1.0 \times 10^{-3}$} & $0.005 \mathrm{~g}$ & 0.59 & 185 & 544 & 48 & 91.17 \\
\hline & $0.01 \mathrm{~g}$ & 1.88 & 40 & 544 & 16 & 97.05 \\
\hline & $0.02 \mathrm{~g}$ & 5.08 & 25 & 544 & 16 & 97.05 \\
\hline
\end{tabular}

Fig. 7 Effect of concentration of Carboxylic acids on the rate of degradation under UV light $[\mathrm{A}]$ oxalic acid, [B] formic acid, and [C] acetic acid

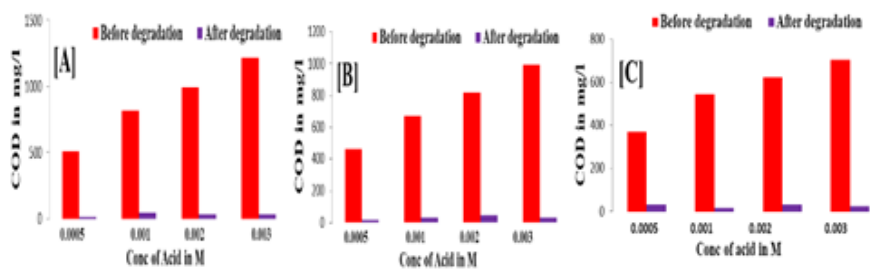

Fig. 8 Effect of concentration of Carboxylic acid on COD values under UV light $[\mathrm{A}]$ oxalic acid, [B] formic acid, and [C] acetic acid

Table 3 Effect of catalyst loading on the photodegradation of carboxylic acids under UV light

* for $95 \%$ Degradation
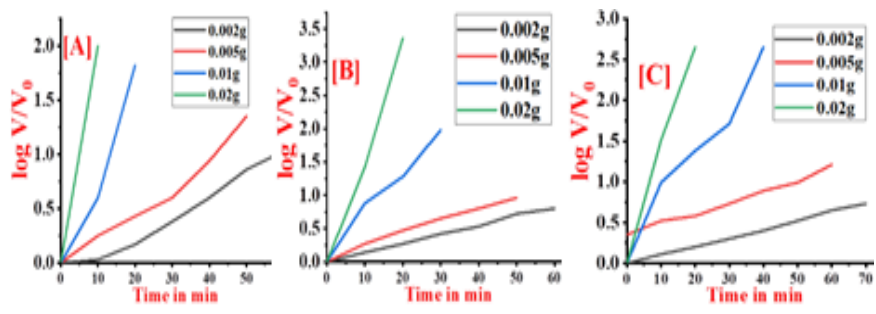

Fig. 9 Effect of catalyst loading on the rate of degradation of carboxylic acids under UV light $[\mathrm{A}]$ oxalic acid, $[\mathrm{B}]$ formic acid, and $[\mathrm{C}]$ acetic acid 


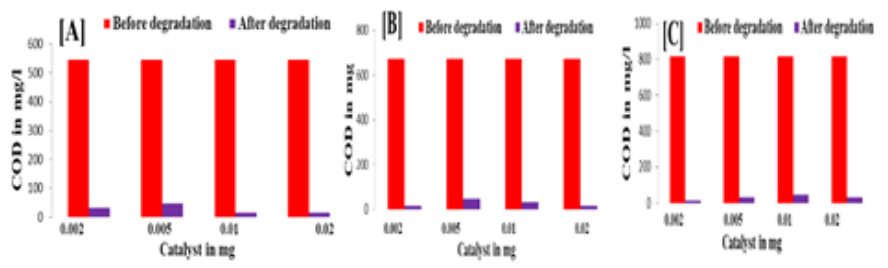

Fig. 10 Effect of catalyst loading of carboxylic acids on COD values under UV light [A] oxalic acid, [B] formic acid, and [C] acetic acid

\subsubsection{Effect of Temperature}

Temperature is one of the essential factors which effects the rate of photodegradation. It is clear that the increase in temperature increases the acid degradation, and observed that the rate of appearance of colour is not very significant at low temperature. However, the reaction is more significantly influenced at high temperature since the diffusion rate increased with temperature an increase of temperature could bring about an increase in the degradation rate (Table 4, Figs. 11 and 12)

Table 4 Effect of temperature on the photodegradation of carboxylic acids under UV light

\begin{tabular}{|c|c|c|c|c|c|c|}
\hline \multirow{2}{*}{$\begin{array}{l}\text { Carboxylic } \\
\text { acids }\end{array}$} & \multirow[t]{2}{*}{ Catalyst } & \multirow[t]{2}{*}{ Temp., K } & \multirow[t]{2}{*}{$10^{3} \mathrm{k} \mathrm{sec}^{-1}$} & \multicolumn{2}{|c|}{ COD Values in $\mathrm{mg} / \mathrm{L}$} & \multirow{2}{*}{$\begin{array}{l}\text { Efficiency } \\
-\%\end{array}$} \\
\hline & & & & Before & After & \\
\hline Oxalic acid & & 298 & 1.08 & 816 & 16 & 98.03 \\
\hline \multirow[t]{3}{*}{$1.0 \times 10^{-3}$} & & 308 & 3.54 & 816 & 32 & 96.07 \\
\hline & $\stackrel{\pi}{2}$ & 318 & 4.44 & 816 & 48 & 94.11 \\
\hline & $\underset{\vec{\pi}}{\vec{\pi}}$ & 328 & 7.83 & 816 & 16 & 98.03 \\
\hline \multirow{4}{*}{$\begin{array}{l}\text { Formic acid } \\
1.0 \times 10^{-3}\end{array}$} & $\Xi$ & 298 & 0.97 & 672 & 24 & 96.42 \\
\hline & 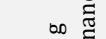 & 308 & 2.43 & 672 & 16 & 97.61 \\
\hline & - 0 & 318 & 3.50 & 672 & 48 & 92.85 \\
\hline & $\dot{0} \cdot \bar{x}$ & 328 & 4.27 & 672 & 64 & 90.47 \\
\hline \multirow{4}{*}{$\begin{array}{l}\text { Acetic acid } \\
1.0 \times 10^{-3}\end{array}$} & छ & 298 & 0.66 & 544 & 16 & 97.05 \\
\hline & 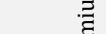 & 308 & 1.88 & 544 & 32 & 94.11 \\
\hline & $\frac{\tilde{\pi}}{\pi}$ & 318 & 2.11 & 544 & 16 & 97.05 \\
\hline & & 328 & 3.36 & 544 & 16 & 97.05 \\
\hline
\end{tabular}

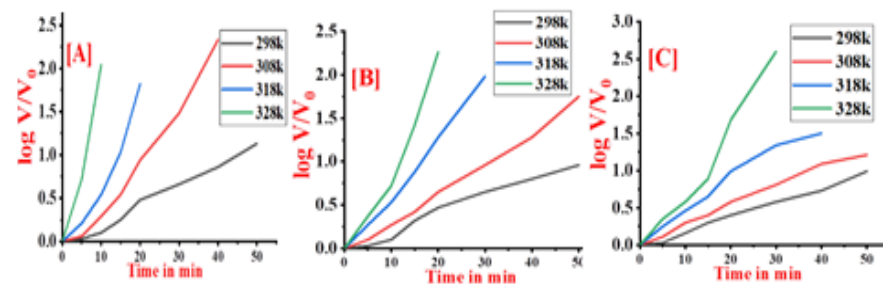

Fig. 11 Effect of temperature on the rate of degradation of carboxylic acids under UV light $[\mathrm{A}]$ oxalic acid, $[\mathrm{B}]$ formic acid, and $[\mathrm{C}]$ acetic acid

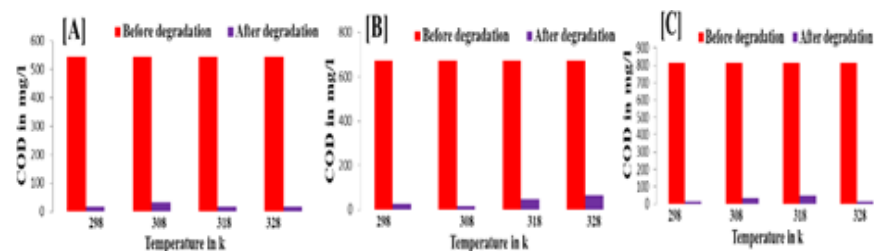

Fig. 12 Effect of temperature of carboxylic acids on COD values under UV light [A] oxalic acid, [B] formic acid, and [C] acetic acid

\subsection{Activation Parameters for the Oxidation of Carboxylic Acids}

Attempts were made to arrive at a linear free energy relation for the oxidation/photodegradation of carboxylic acids by using cadmium oxide nanoparticles. Test of Taft equation was obtained for plot of $\operatorname{logk} \mathrm{v} / \mathrm{s} \sigma^{*}$. The following regression equation $\log \mathrm{k}=0.226 \sigma^{*}-2.75(\mathrm{r}=0.993)$ was obtained (Fig. 13). The positive value of polar constant $\rho^{*}$, although small, it indicates that electron donating capacity decreases the rate of degradation it is seen from Table 5 . The rate of oxidation/degradation of carboxylic acids by using cadmium oxide nano particles decrease in the order.

\section{Oxalic acid $>$ Formic acid $>$ Acetic acid}

The activation energy value is highest for the slowest reaction and viceversa, indicating that the reaction is enthalpy controlled. The activation enthalpies $\left(\Delta \mathrm{H}^{\#}\right)$ and entropies $\left(\Delta \mathrm{S}^{\#}\right)$ for the degradation carboxylic acids through oxidation are linearly related. Form the slope of the plot of $\Delta \mathrm{H}^{\#}$ $\mathrm{v} / \mathrm{s} \Delta \mathrm{S}^{\#}(\mathrm{r}=0.993)$ the isokinetic temperature $(\beta)$ was calculated to be 333 $\mathrm{K}$. This is further verified by employing the Exner criterion [34] with a plot https://doi.org/10.30799/jnst.278.19050505 of $\operatorname{logk}_{1} 318 \mathrm{~K} \mathrm{v} / \mathrm{s} \log \mathrm{k}_{2} 328 \mathrm{~K}$ which is linear. From the Exner slope $\beta$ was found to be $340 \mathrm{~K}$. The value of $\beta$ is higher than the temperature range employed in the present work, supporting the fact that the oxidation of carboxylic acids is enthalpy controlled. The fairly high negative values of entropy of activation point towards the formation of fairly rigid activated state. The constancy of $\Delta \mathrm{G}^{\#}$ values indicates that the carboxylic acids undergo oxidation/ degradation via an identical mechanism.

Table 5 Thermodynamic parameters for carboxylic acids

\begin{tabular}{llllll}
\hline Carboxylic acids & $\begin{array}{l}\text { Temp., } \\
\mathrm{K}\end{array}$ & $\begin{array}{l}\Delta \mathrm{H}^{\#} \\
\mathrm{kJmol}^{-1}\end{array}$ & $\begin{array}{l}\Delta \mathrm{S}^{\#} \\
\mathrm{Jk}^{-1} \mathrm{~mol}^{-1}\end{array}$ & $\begin{array}{l}\Delta \mathrm{G}^{\#} \\
\mathrm{kJmol}^{-1}\end{array}$ & $\begin{array}{l}\mathrm{Ea} \\
\mathrm{cal}\end{array}$ \\
\hline \multirow{4}{*}{ Oxalic acid } & 298 & & & & \\
& 308 & 37.39 & -173.35 & 91.63 & $9.56 \times 10^{3}$ \\
& 318 & & & & \\
Formic acid & 328 & & & & \\
& 298 & & & & $12.44 \times 10^{3}$ \\
& 308 & 49.44 & 137.60 & 92.52 & \\
Acetic acid & 318 & & & & \\
& 328 & & & & \\
& 298 & & & & \\
& 308 & 59.02 & 109.13 & 93.21 & $14.73 \times 10^{3}$ \\
& 318 & & & & \\
\hline
\end{tabular}
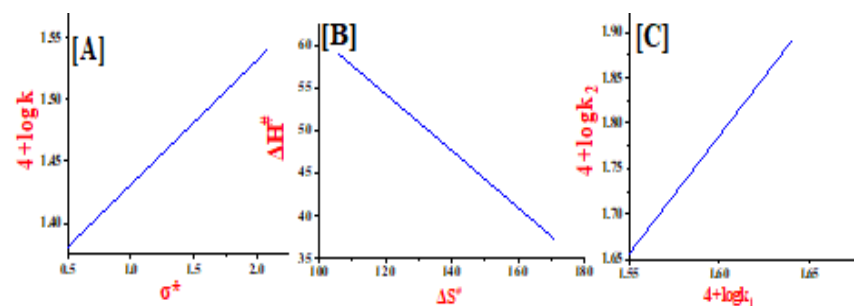

Fig. 13 [A] Taft LFER for carboxylic acids, [B] isokinetic temperature relationship for carboxylic acids and [C] Exner criterion for carboxylic acids

\subsection{Effect of Light Intensity}

The photodegradation rate constant in UV light is compared with sunlight. It is perceived that the photodegradation rate constant is increased in UV light compared to sunlight for prepared cadmium oxide nanomaterial. The reason beyond that is when a photon occurrence on a semiconductor ( $\mathrm{CdO}$ ) energy that overtake the band gap energy of the semiconductor. An electron is jump up from the valence band to the conduction band leaving a hole in the valence band .The excited state conduction band electrons and valence band hole can recombined and dissipate energy in the form of heat and get trapped into the metastable surface states, respectively with electrons acceptors and donors that happened to be adsorbed on the semiconductor surface .The stored energy is dissipated within a few nanoseconds by recombination in the absence of suitable $\mathrm{e}^{-} / \mathrm{h}^{+}$scavengers .If a suitable scavenger is available to trap the electron recombination is prevented i.e. subsequent redox reaction may occur. Therefore, the cadmium oxide nanomaterial acts as a very good photocatalyst and is active under UV light compared to sunlight. The rate constant for degradation in sunlight is given in Table 6 and Fig 14. This also supports the observed energy band gap $2.85 \mathrm{eV}$ in the UV visible spectral study.

Table 6 Effect of rate of degradation in sunlight and UV light

\begin{tabular}{|c|c|c|c|c|c|}
\hline $\begin{array}{l}\text { Catalyst } \\
0.01 \mathrm{~g}\end{array}$ & $\begin{array}{l}\text { Concentration } \\
\text { of carboxylic } \\
\text { acids in } \\
0.001 \mathrm{~N}\end{array}$ & $\begin{array}{l}\text { Sunlight } \\
10^{3} \mathrm{k} \mathrm{S}^{-1}\end{array}$ & $\begin{array}{l}\text { Time taken } \\
\text { for } 95 \% \\
\text { Degradation } \\
\text { in min }\end{array}$ & $\begin{array}{l}\text { UV } \\
\text { light } \\
10^{3} \mathrm{k} \\
\mathrm{S}^{-1}\end{array}$ & $\begin{array}{l}\text { Time taken } \\
\text { for } 95 \% \\
\text { Degradation } \\
\text { in min }\end{array}$ \\
\hline Cadmium & Oxalic acid & 1.09 & 55 & 1.53 & 20 \\
\hline oxide & Formic acid & 0.78 & 150 & 1.05 & 30 \\
\hline nanomaterial & Acetic acid & 0.49 & 125 & 0.98 & 40 \\
\hline
\end{tabular}
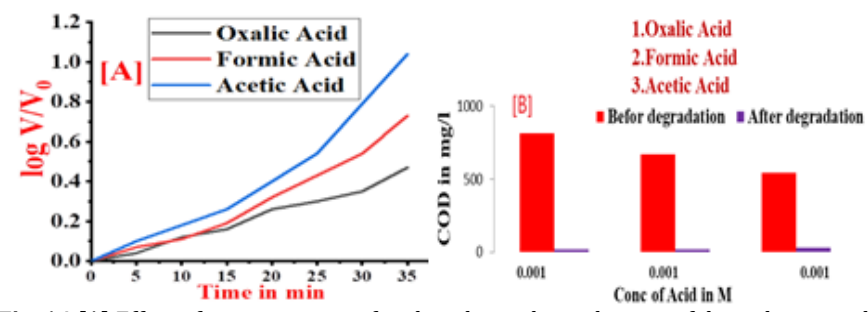

Fig. $14[\mathrm{~A}]$ Effect of concentration of carboxylic acids on the rate of degradation and [B] COD values under sunlight 


\subsection{Reuse of Catalyst}

The reuse of catalyst was examined to see the photodegradation efficiency of the carboxylic acid solutions. After the degradation of acid, the degraded sample was kept outside without expose the UV-light for $8 \mathrm{hr}$ and supernatant liquid sample was decanted. The catalyst was thoroughly washed with double distilled water and reuse for the photodegradation by taking new acid solutions. The reuse of photocatalyst shown almost same degradation efficiency compared to the fresh sample. This can be recommended the photocatalyst can be regenerated and reused.

\subsection{Antibacterial Assay}

The antibacterial susceptibility of compound was evaluated by using the disc diffusion Kirby-Bauer method in Mueller Hinton Agar Plate [35]. All reference bacterial strains were obtained from Microbial Typing Culture Collection (MTCC), Chandigarh, India. Gram-positive Bacillus subtilis (MTCC 2763) and gram-negative Escherichia coli (MTCC 40) were cultured as per the protocol prescribed by MTCC.

\subsection{Antimicrobial Activity - Disc Diffusion Method}

To test disc diffusion assay, $20 \mathrm{~mL}$ of sterilized and molten Mueller Hinton Agar media was poured in to the sterilized petri plates. The reference bacterial strains were cultured overnight at $37{ }^{\circ} \mathrm{C}$ in Mueller Hinton broth and adjusted to a final density of $10^{7} \mathrm{CFU} / \mathrm{mL}$ by 0.5 McFarland standards. $100 \mu \mathrm{L}$ of the pathogenic bacteria cultures were transferred onto plate and made culture lawn. The comparative stability of discs containing Gentamycin was made. Test CdO nanoparticles were loaded into $6 \mathrm{~mm}$ sterile discs and placed on the culture plates and incubated at $37{ }^{\circ} \mathrm{C}$ for 24 hours. By measuring the diameter of the ZOI formed around the disc, the antibacterial efficacy of $\mathrm{CdO}$ nanoparticles was determined. All assays were performed in triplicates.

The antibacterial susceptibility of $\mathrm{CdO}$ nanoparticle was investigated by zone of inhibition by Kirby-Bauer disc diffusion method. Disposable plates inoculated with the Gram-positive and Gram-negative bacteria, such as Bacillus subtilis and Escherichia coli.
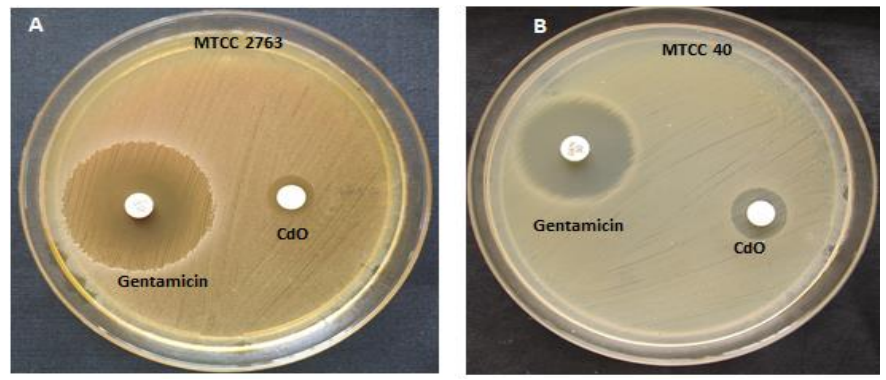

Fig. 15 Zone of inhibition against (A) Bacillus subtilis and (B) Escherichia coli bacteria

Fig. 15 shows the growth inhibition. Compound inhibited bacterial growth by the clear inhibition zone (a concentration of $30 \mu \mathrm{g} / \mathrm{mL}$ ). The diameter of inhibition zones (in millimeters) around the Compound against test strain are shown in Table 7.

Table 7 Antibacterial effect of CdO nanoparticles by zone of inhibition (mm) against test strains

\begin{tabular}{lll}
\hline Test Bacteria & CdO Nanoparticles & $\begin{array}{l}\text { Positive control Gentamycin } \\
(30 \mu \mathrm{g} / \mathrm{mL})\end{array}$ \\
\hline Bacillus subtilis MTCC 2763 & $11.06 \pm 0.18$ & $30.06 \pm 0.04$ \\
Escherichia coli MTCC 40 & $11.71 \pm 0.02$ & $25.16 \pm 0.11$ \\
\hline
\end{tabular}

Note: Values are the mean \pm SE of triplicate experiments

\section{Conclusion}

In the present paper, cadmium oxide nanomaterials are synthesized by electrochemical method. The electrochemically synthesized Cadmium oxide nanomaterials were characterized by UV-VIS spectra, SEM, EDAX, XRD and FT-IR spectra. The photodegradation by this semiconductor offers a green technology for removal of organic dyes present in waste water and industrial effluents. The photocatalytic study for the synthesized cadmium oxide nanomaterial was investigated by the kinetics of photodegradation of carboxylic acids by volumetric method against $\mathrm{NAOH}$ solution. Kinetics of photodegradation of carboxylic acids recommended that the dematerialize of acids follows $1^{\text {st }}$ order kinetics. The photodegradation rate in UV light is high compared to sunlight hence the synthesized Cadmium oxide nanomaterials acts as a very good photocatalyst and is active under UV light. The completeness of https://doi.org/10.30799/jnst.278.19050505 degradation was confirmed by COD measurement. The COD values revealed that $-96 \%$ of the acid had been degraded. The synthesized nanomaterials show appreciably good inactivation of different strains of bacteria.

\section{Acknowledgement}

H.C. Charan Kumar is grateful to UGC-BSR Programme for the award of a project fellow and thanks the IOE, UPE, CPEPA, DST-PURSE and university of Mysore. R. Shilpa thanks University of Mysore for providing research facilities.

\section{References}

[1] C. Sravani, K.T.R. Reddy, O.M. Hussain, P.J. Reddy, Investigations on n-CdO/pCdTe thin film heterojunctions, J. Solar. Energy. Soc. India 1 (1996) 61-69.

[2] L.M. Su, N. Grote, F. Schmitt, Diffused planar in bipolar transistor with a cadmium oxide film emitter, Electron. Lett. 20 (1984) 716-721.

3] A. Pricilla Jeyakumari, P. Siva, P. Pachamuthu, M. Revathi, Structural, optical and antibacterial activity of pure and cadmium doped zinc oxide nano particles, IOSR Jour. Appl. Phys. 9 (2017) 80-86.

[4] M.L. Dinesha, G.D. Presanna, C.S. Naveen, H.S. Jayanna, Structural and dielectric properties of Fe doped ZnO nanoparticles, Int. J. Phys. 87(2) (2013) 147-153.

[5] A.S. Aldwayyan, F.M. Al-Jekhedab, M. Al-Noaimi, B. Hammouti, T.B. Hadda, et al., Synthesis and characterization of $\mathrm{CdO}$ nanoparticles starting from organometalic dmphen-CdI 2 complex. Int. J. Electrochem. Sci. 8 (2013) 1050610514

[6] R. Kondo, H. Okimura, Y. Sakai, Electrical properties of semiconductor photodiodes with semitransparent films, Jpn. J. Appl. Phys. 10 (1971) 15471556.

[7] Sunny S. Tarve, Swapnil G. Prabhulkar, Raju M. Patil, Nickel oxide and nicke sulphide nanomaterials: promising catalysts for the decomposition of hazardous dye, Ind. J. Res. 5 (2016) 196-199.

[8] J. Charlesbabu, K. Gopalakrishnan, M. Elango, Spin coated cadmium doped zinc oxide thin films: Preparation, structural, optical and electrical characterization, Ind. J. Sci. Technol. 9(35), (2016) 1-5.

[9] U. Ozgur, D. Hofstetter, H. Morkoc, ZnO devices and applications: a review of current status and future prospects, Proc. IEEE 98(7) (2010) 1255-1268.

[10] Sannaiah Ananda, H.C Charan Kumar, R. Shilpa, Synthesis and characterization of NiO nanoparticles by electrochemical method: Photodegradation kinetics of indigo carmine dye and study of antibacterial activities of $\mathrm{NiO}$ nanoparticles, J. Applicable Chem. 8 (2) (2019) 622-633.

[11] S. Balamurugan, A.R. Balu, K. Usharani, M. Suganya, S. Anitha, et al., Synthesis of CdO nanopowders by a simple soft chemical method and evaluation of their antimicrobial activities, Pacific Sci. Rev. A 18 (2016) 228-232.

[12] M. Farbod, M. Kajabafvala, Effeect of nanoparticle surface modification on the adsorption- enhanced photocatalysis of $\mathrm{Cd} / \mathrm{TiO}_{2}$ nanocomposite, Powder Technol. 239(1) (2013) 434-440.

[13] V.E. Henrich, P.A. Cox, The surface chemistry of metal oxides, Cambridge University Press, Cambridge, UK, 1994.

[14] A. Salem, Silver-doped cadmium oxide nanoparticles: Synthesis, structural and optical properties, Eur. Phys. J. Plus 129 (2014) 263-275

[15] T.J. Coutts, T.O. Mason, J.D. Perkins, D.S. Ginley, Transparent conducting oxides: status and opportunities in basic research, National Renewable Energy Laboratory, $195^{\text {th }}$ Meeting of the Electrochemical Society Seattle, Washington, 1999.

[16] B. Goswami, A. Choudhury, Enhanced visible luminescence and modification in morphological properties of cadmium oxide nanoparticles induced by annealing, J. Exp. Nanosci. 10(12) (2015) 900-910.

[17] K. Manickathai, S.K. Viswanathan, M. Alagar, Synthesis and characterisation of CdS and CdO nanoparticles, Indian J. Pure Appl. Phys. 46 (2008) 561-564.

[18] A.S. Lanje, R.S. Nighthoujam, S.J. Sharma, R.B. Pode, Luminescence and electrical resistivity properties of cadmium oxide nanoparticles, Indian J. Pure Appl. Phys. 49 (2011) 234-238.

[19] Hiten Sarma, Dhruba Chakrabortty, K.C. Sarma, Structural characterization of cadmium oxide nanoparticles by means of X-ray line profile analysis, International conference on electronic devices, circuits, applied electronics and communication technology, J. Basic Appl. Eng. Res. 2(20) (2015) 1773-1780.

[20] G. Chaitanya Lakshmi, S. Ananda, Somashekar, C. Ranganathaiah, Synthesis of $\mathrm{ZnO} / \mathrm{ZrO}_{2}$ nanocomposites by electrochemical method and photocatalytic degradation of Fast green dye, paper dyeing and printing press effluent, Int. J. Adv. Mater. Sci. 3 (2012) 221-237.

[21] K. Byrappa, A.K. Subramani, S. Ananda, K.M.L. Rai, R. Dinesh, M. Yoshimura, Photocatalytic degradation of rhodamine B dye using hydrothermally synthesized ZnO, Bull. Mater. Sci., 29 (2006) 1-6.

[22] Subhash Kondawar, Ritu Mahore, Ajay Dahegaonkar, Shikha Agrawal, Electrical conductivity of cadmium oxide nanoparticles embedded polyaniline nanocomposites, Adv. Appl. Sci. Res. 2(4) (2011) 401-406.

[23] X.Y. Ma, G.X. Lu, B.J. Yang, Study of the luminescence characteristics of cadmium sulfide quantum dots in a sulfonic group polyaniline (SPAn) film, Appl. Surf. Sci. 187 (2002) 235-238.

[24] X.R. Ye, C. Daraio, C. Wang, J.B. Talbot, Room temperature solvent-free synthesis of monodisperse magnetite nanocrystals, J. Nanosci. Nanotechnol. 6 (2006) 852-856.

[25] T.P. Sharma, D. Patidar, N.S. Saxena, K. Sharma, Measurement of structural and optical band gaps of $\mathrm{Cd}_{1-\mathrm{x}} \mathrm{Zn} \mathrm{x}$ ( $\mathrm{x}=4$ and 6) nanomaterials, Ind. J. Pure Appl. Phys. 44 (2006) 520-615.

[26] B. Cullity, Elements of X-ray diffraction, A.W.R.C Inc, Massachusctts, 1967. 
[27] Ramna Tripathi, Alo Dutta, Sayantani Das, Akhilesh Kumar, T.P. Sinha, Dielectric relaxation of CdO nanoparticles, Appl. Nanosci. 6 (2016) 175-18.

[28] Taimur Athar, S.S. Mahamad Shafi, Aleem Ahmed Khan, Soft chemical process for synthesis of CdO nanoparticles, Mater. Focus 3 (2014) 397-400.

[29] Shahid Khan Durrani, Sumaira Naz, Mazhar Mehmood, Muhammad Nadeem, Muhammad Siddique, Structural, impedance and Mossbauer studies of magnesium ferrite synthesized via sol-gel auto-combustion process, J. Statistic. Comp. Simul. 12 (2015) 1-28.

[30] L. Wei, C. Shifu, Z. Wei, Z. Sujuan, Titanium dioxide mediated photocatalytic degradation of methamidophos in aqueous phase, Jour. Hazard. Mater. 164 (2009) 154-160.

[31] Rakesh, Sannaiah Ananda, Netkal M. Made Gowda, Kithanakere Ramesh Raksha, Synthesis of niobium doped $\mathrm{ZnO}$ nanoparticles by electrochemical method: characterization, photodegradation of indigo carmine dye and antibacterial study, Adv. Nanopart. 3 (2014) 133-147.

[32] N. Neelakandeswari, G. Sangami, N. Dharmaraj, Nam Ki Taek, Hak Yong Kim, Spectroscopic Investigations on the photodegradation of toluidine blue dye using cadmium sulphide nanoparticles prepared by a novel method, Spectrochim. Acta A 78(5) (2011) 1592-1598.

[33] K.R. Raksha, Sannaiah Ananda, An investigation on kinetics of photocatalysis, electrical property and biological activity of electrochemically synthesized ZnS and Ru: ZnS nano photocatalysts, J. Applicable Chem. 3(1) (2014) 397-412.

[34] O. Exner, On the enthalpy-entropy-relationship, Coll. Czech Chem. Commun. 29 (1964) 1094-1113.

[35] A.W. Bauer, W.M.M. Kirby, J.C. Sherris, M. Turck, Antibiotic susceptibility testing by a standardized single disk method, Am. J. Clin. Pathol. 45 (1966) 493496. 